\title{
Sternum Fraktürleri: 55 Olgunun Retrospektif Analizi
}

\author{
Sternal Fractures: Retrospective Analysis of 55 Cases
}

\author{
Ulaș Kumbasar ${ }^{1}$, Arif Osman Tokat ${ }^{2}$, Sezgin Karasu² ${ }^{2}$ Hüseyin Çakmak ${ }^{3}$, Sevil Tokat ${ }^{4}$, Hacı \\ Alper Uzun ${ }^{5}$, Jale Karakaya6.
}

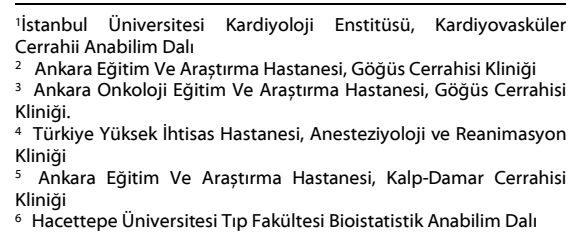

4 Türkiye Yüksek intisas Hastanesi, Anesteziyoloji ve Reanimasyon

Kliniği

5 Ankara Eğitim Ve Araștırma Hastanesi, Kalp-Damar Cerrahisi

Kliniğ

6 Hacettepe Üniversitesi Tıp Fakültesi Bioistatistik Anabilim Dalı

Amaç: Sternum fraktürleri (SF) seyrek rastlanmakla birlikte ciddi mediastinal yaralanma ile birlikte görülebildiğinden önemli bir morbidite ve mortalite nedenidir. Bu çalıșmada künt travmaya bağlı gelișen sternum fraktürlerinde etyolojik nedenlerin belirlenmesi ve prognozda etkili faktörlerin incelenmesi amaçlanmıștır.

Materyal ve Metod: 2003 ile 2009 yılları arasında kliniğimizde künt travma sonucu sternum fraktürü tanısı ile tedavi edilen 55 hasta incelendi.

Bulgular: Hastaların 40'ı erkek (\%72.7), 15'i (\%27.3) kadındı. Yaș ortalaması 38.32 \pm 11.88 olarak hesaplandı (19-64). En sık rastlanan etyolojik neden trafik kazası olarak belirlendi. Ancak hastalardan sadece 4'ünde emniyet kemerine bağlı SF gözlendi. Íkinci en sık travma nedeni darp olarak belirlendi. Hastalardan 18'inde izole (\%32.7), 37'inde komplike (\%67.3) SF saptandı. İzole SF saptanan 18 hastadan sadece 6'sı hospitalize edildi. Esslik eden travmatik patolojisi olan hastaların tamamı yatarak tedavi edildi. Hastalardan 4'ünde pnömotoraks, 6'sında hemopnömotoraks saptandı ve tüp torakostomi ile tedavi edildi. İzole SF veya sadece toraks patolojisi ile birlikte SF nedeniyle hastanede yatarak tedavi edilen hastaların, kafa travması ve/veya extremite fraktürü olan hastalara göre istatistiksel olarak anlamlı șekilde daha kısa yatıș süresine sahip olduğu görüldü $(p<0.05)$.

Sonuç: İole SF benign bir antite olarak değerlendirilebilir ve ayaktan tedavi edilebilen bir durumdur. Ancak genel vücut travması ile birlikte SF, travmanın șiddetinin yüksek olduğunu gösterir ve dikkatli izlem ve tedavi gerektirir.

Anahtar Sözcükler: Sternum fraktürü, künt travma, toraks travması.

Aim: Although the sternal fractures (SF) are seen rare, it is an important cause of mortality and morbidity because it can accompany mediastinal traumas. In this study we aimed to determine the etiological causes of sternal fractures due to blunt traumas and to analyze the factors, that effect on prognosis.

Material and Method: We analyzed the 55 patients who underwent treatment for sternal fracture due to blunt trauma between 2003 and 2010.

Results: There were 40 male $(72.7 \%)$ and 15 female $(27.3 \%)$ patients. The mean age was $38.32 \pm 11.88$ (19-64). The most common etiological cause was traffic accidents. However, there were only 4 patients diagnosed as sternal fracture caused by safety seat belts. The second most common cause of trauma was assaults. $18(32.7 \%)$ patients had simple sternal fracture, whereas $37(67.3 \%)$ patients had complicated SF. Only 6 of the 18 patients with simple sternal fracture were hospitalized. All of the patients with concomitant traumatic pathology were hospitalized. Pneumothorax was diagnosed in 4 patients and hemo-pneumothorax in 6; all of the patients were treated with tube thoracostomy. The duration of hospital stay was statistically significant in patients with simple SFs or with concomitant thoracic pathologies then the patients who had concomitant head traumas and/or extremity fractures $(p<0.05)$.

Conclusions: Simple sternal fractures can be considered as benign entity and treated as outpatients. However sternal fractures along with general body traumas, indicate the severity of the trauma and requires a careful follow up and management.

Key Words: Sternal fracture, blunt trauma, thoracic traumas.

Künt travmalı hastalarda sternum fraktürü (SF) seyrek görülür. Trafik kazalarında \%4 ve künt travmalarda $\% 3$ ile $\% 8$ oranında gözlenir (1-3).
Sternum yerleşimi ve yapısı göz önüne alındığında toraks içindeki kalp ve akciğerler gibi hayati organlar için koruma görevi yapmaktadır. Bu nedenle 
SF'de kırı̆̆ın kendisinden çok SF'ne bağlı gözlenebilecek yaralanmalar önemlidir $(2,3)$.

$\mathrm{Bu}$ araştırma da 112 acil yardım hizmeti veren hastanemiz acil servisinde 7 ylllik dönemde travma nedeniyle başvuran hastalardan yapilan incelemeler sonucunda sternum fraktürü saptanan hastalar incelenmiștir. Hastalarda etiyoloji ve prognostik faktörler değerlendirilmiş, uygulanan tedavi sonuçlarının ortaya konması amaçlanmiştır.

\section{Hastalar ve Yöntem}

Çalışmamızda hastanemiz acil servisine 2003 ile 2009 y1llar1 arasinda travma sonucu SF saptanan 55 hasta incelendi. Hastanemiz acil servis kayitlar1, adli kayıtlar ve klinik kayıtlarımızdan hastaların yaş, cinsiyet, travmanın şekli, uygulanan tedavi, tedavinin sonucu, hastanede yatış süreleri ve travmaya bağlı sternum fraktürüne eşlik eden patolojiler belirlendi.

Tüm hastalara acil servise başvurduklarında posteroanterior akciğer grafisi ve lateral sternum grafisi çekildi. Sadece şüpheli durumlarda toraks bilgisayarlı tomografisi ile inceleme yapıld1. Tüm hastalara standart elektrokardiografi (EKG) çekildi, kreatin kinaz $(\mathrm{CK})$ ve kreatin kinaz myokardial band (CK-MB) değerleri saptandı ve ilk 12 saat monitorize edildiler. Kalp yaralanması şüphesi olan hastalar ekokardiografi ile değerlendirildi. Abdominal travmaya veya kafa travmasina bağlı kontrendikasyon yok ise ağrı tedavisi uygulandi. 12 saat sonra posteroanterior akciğer grafisi, sternum grafisi ve EKG tekrarlandi.

Geçirilen travmaya bağlı toraks veya diğer sistemlerde herhangi bir komplikasyona rastlanmayan sadece 1 veya 2 kot fraktürü ile birlikte görülen ve paradoksal solunum hareketi olmayan hastalar izole SF kabul edildi. Bu hastalar analjezik tedavi ve solunum egzersizi önerilerek 1 hafta sonra kontrole gelmek üzere taburcu edildi. Sternum fraktürüne eşlik eden komplikasyonlar için kliniğimiz veya ortopedi, genel cerrahi ve beyin cerrahisi gibi travma hastası takip eden kliniklerden herhangi birinin yatış endikasyonu vermesi durumunda hasta komplike SF olarak kabul edildi. Kafa travmasi ile extremite fraktürü birlikte gözlenen 7 hasta kafa travmasina ait patoloji daha hayati ve öncelikli olduğu için beyin cerrahisi servisinde izlendi ve çalışmada kafa travması bulunan hastalar grubunda değerlendirildi.

\section{İstatistiksel Analiz}

Sayısal değişkenler için, tanımlayıcı istatistik olarak ortalama \pm standart sapma (SS), ortanca (Minimum (min)Maximum (max)) kullanıldı. Kategorik değişkenler için sayı, \% verildi. İki grup karşılaştırması için MannWhitney U testi kullanıldı. İstatistiksel açıdan $\mathrm{p}<0.05$ anlamlı kabul edildi. Tüm analizler SPSS 15.0 programı yardımı ile yapıldı.

\section{Bulgular}

Hastaların $\quad 40^{\prime} 1$ erkek (\%72.7), 15'i (\%27.3) kadındı. Yaș ortalaması 38.32 \pm 11.88 olarak hesaplandi. En genç hasta 19, en yaşlı hasta 64 yaşında idi. Şuuru açı tüm hastalarda sternum üzerinde hassasiyet saptand. 20 hastada (\%36.4) sternum üzerinde ekimoz ve palpasyonla deformite gözlendi. Hastaların tamamina posteroanterior akciğer grafisi ve sternum grafileri rutin olarak çekildi. 46 hastaya (\%83.6) direkt grafilerle tanı kondu. 9 hastaya $(\% 16.4)$ ise toraks bilgisayarlı tomografisi ile SF tanısı kondu (Şekil 1).

Sternum fraktürünün tek patolojik bulgu olarak saptandığ hastalar izole SF olarak değerlendirildi. Ek organ yaralanması bulgusu olan hastalar komplike SF olarak değerlendirildi. Hasta- lardan 18'inde izole (\%32.7), 37'inde komplike (\%67.3) sternum fraktürü saptand1. Etiyolojik faktörler incelendiğinde en sik rastlanan nedenin 25 hastada trafik kazası (\%45.5) olduğu görüldü. 17 hastada (\%30.9) darp ve 13 hastada da (\%23.6) düşme sonucu SF geliştiği görüldü (Tablo 1).

Otuzbeş hastanın komplike SF olan hastalar olduğu görüldü. Komplike SF saptanan hastalara en sik kot fraktürünün eşlik ettiği saptandı (20 hasta \%34,6). Kot fraktürü saptanan bu hastalardan 4'ünde pnömotoraks ve 6 hastada da hemopnömotoraks saptand1 ve tüp torakostomi uyguland. Tüp torakostomi uygulanan hastaların tamamı beyin cerrahisi ve ortopedi kliniklerinde yatarak takip edildi. 10 hastada kafa travması (\%18.2), 6 hastada ekstremite fraktürleri (\%10.9) olduğu görüldü. Hiçbir hastamızda kardiak patoloji saptanmadi.

Hastalardan 41'inin yatarak tedavi edildiği belirlendi. Bunlardan 6'sının izole SF olmasina rağmen sternumda deplase fraktür (3 hasta), ilave kot fraktürleri, yaş, hipertansiyon veya diyabet gibi ek patolojiler nedeniyle yatırıldığ1 görüldü. Toplam 10 hastada (\%18.2) deplase SF saptandi. Bu hastalar yattıkları süre içinde sırtın ortasına bir yastık ile destek yapilarak sternum ekstansiyona getirilerek kırık redükte edilmeye çalışıldı. Taburcu olanlara aynı tedaviyi evde uygulamaları önerildi.

İzole SF saptanan hastalarda ortalama hastanede yatış süresi $3.17 \pm 3.37$ gün iken, komplike hastalarda bu süre 16.51 99.55 gün olarak belirlendi. Ek patolojik bulgu saptanan hastalar incelendiğinde toraks patolojisi olan hastaların kafa travması geçiren ve ekstremite fraktürü olan hastalardan

Tablo 1: İzole ve komplike sternum fraktürlerinin etyolojik faktörlere göre dağllımı.

\begin{tabular}{|c|c|c|c|c|c|c|}
\hline Sternum Fraktürü & \multicolumn{2}{|c|}{ İzole fraktür } & \multicolumn{2}{c|}{ Komplike Fraktür } & \multicolumn{2}{c|}{ Toplam } \\
\hline Etyolojik faktör & Say1 & $\mathbf{\%}$ & Say1 & $\mathbf{\%}$ & Say1 & $\mathbf{\%}$ \\
\hline Trafik kazası & 5 & 9.1 & 20 & 36.4 & $\mathbf{2 5}$ & $\mathbf{4 5 . 5}$ \\
\hline Darp & 6 & 10.9 & 11 & 20.0 & $\mathbf{1 7}$ & $\mathbf{3 0 . 9}$ \\
\hline Düşme & 7 & 12.7 & 6 & 10.9 & $\mathbf{1 3}$ & $\mathbf{2 3 . 6}$ \\
\hline Toplam & $\mathbf{1 8}$ & $\mathbf{3 2 . 7}$ & $\mathbf{3 7}$ & $\mathbf{6 7 . 3}$ & $\mathbf{5 5}$ & $\mathbf{1 0 0}$ \\
\hline
\end{tabular}


istatistiksel olarak anlamlı şekilde daha kısa süre hastanede yattığı görüldü $(\mathrm{p}<0.001)$ (Tablo 2). Etiyolojik nedene göre yapılan istatistiksel analizde de trafik kazası nedeni ile gelen SF'li hastaların darp ve düşmeye bağlı başvuran hastalara göre istatistiksel olarak anlamlı şekilde daha uzun süre hastanede yattığı görüldü ( $\mathrm{p}<0.001)$.

İzole SF kabul edilen hastalarda morbidite ve mortaliteye rastlanmadi. Hastalar konservatif yaklaşımlarla tedavi edildiler. Toplam 10 hastaya (\%18.2) toraks içi patolojiler nedeni ile tüp torakostomi uygulandi. Torakotomi veya sternum stabilizasyonuna hiçbir hastada gerek duyulmadi.

Kafa travmasi olan 3 hastada ve ekstremite fraktürü olan 1 hastada ileri derecede paradoksal solunum gözlenmesi ve takiplerinde hastaların solunum yetmezliğine girmesi nedeniyle ventilatör tedavisi uyguland. Kafa travmasının eşlik ettiği 2 hasta subaraknoid kanama nedeniyle ventilatördesteği altında iken exitus oldu

\section{Tartışma}

Sternum fraktürlerinde etyolojik faktör büyük oranda trafik kazalarıdır $(4,5)$. Richardson ve ark.(6) bu oran1 \%87.5 olarak bildirmektedir. Emniyet kemerine bağlı torasik travma önemli bir etken olarak gösterilmektedir (4,5). Ancak bizim serimizde saptadığımız

\section{SS:standart sapma}

25 hastanın 18'i yaya olarak trafik kazasına karıştığından etyolojide trafik kazasının önemli bir faktör olduğunu ancak emniyet kemerinin etkili bir faktör olmadığını düşünüyoruz.

Sternum fraktürü şuuru açık hastada sternum üzerinde direkt ve indirekt şiddetli ağrı ile kendini belli eder. Fizik muayenede palpasyonla sternum üzerinde düzensizlik ve basamak belirtisi alınabilir. Ekimoz, hematom ve kontüzyon görülebilir (5). Radyolojik olarak mutlaka yan ve oblik sternum grafileri ile değerlendirmek gerekir.
Ön arka grafide eşlik eden mediastinal yaralanmayı ve spinal hasar1 göstermesi bakımından önemlidir (6-8). Hastanemiz acil servisinde özellikle travmalı hastalarda posteroanterior akciğer grafisi ve sternum grafileri rutin olarak çekilmekte ve hastalar grafileri çekilmiş olarak konsülte edilmektedir. Tüm hastalar tanı aşamasında direkt grafiler değerlendirilmiş ve 46 hastada (\%83.6) SF tanisı direkt grafi ile konmuştur. Şüpheli olgularda veya ek patolojik lezyon düşünülen hastalarda toraks bilgisayarlı tomografisi çekilmiş ve direkt grafide SF saptanamayan 9 hastaya (\%16.4) tanı konmuştur.

Velissaris ve ark.(9) hastaların \%11'inde deplase fraktür bildirmektedir. Bizim serimizde deplase fraktür, 3'ü izole fraktürü olan hastalarda olmak üzere 10 hastada (\%18.2) saptand1. Bu hastalara yattıkları süre içinde ilk olarak Çelik ve $\operatorname{ark}(10)$. tarif ettiği şekilde sirta sternumu ekstansiyona getirecek bir destek ile yatmaları sağlandı ve redüksiyona faydası görüldü.

SF'de cerrahi tedavi nadiren gereklidir. Bazı hastalarda ileri derecede paradoksal solunum nedeniyle stabilizasyon uygulanabilir $(1,2,10)$. İleri derecede kompresyona bağlı kozmetik nedenlerle de cerrahi düzeltme yap1labilir (11). Ancak bizim serimizde hiçbir hastaya cerrahi stabilizasyon veya korreksiyon yapilmadi.

SF'de perikardial tamponad, mediastinal hematom, mediastinal apse ve iyileşmede gecikmeye bağlı osteomiyelit gözlenebilir (12,13). Ancak

Tablo 2: Hastada SF'ne ek olarak saptanan patolojik yaralanma türleri ve yatış sürelerinin dağılımı.

\begin{tabular}{|l|c|c|c|c|c|l|l|}
\hline & \multicolumn{2}{|c|}{$\begin{array}{c}\text { Hasta } \\
\text { sayıs1 }\end{array}$} & \multicolumn{5}{c|}{ Yatı̧ süresi } \\
\hline Ek travma türü & Say1 & $\%$ & Ortalama & SS & Ortanca & Min & Max \\
\hline Kosta fraktürü & 20 & 34.6 & 11.20 & 4.12 & 10.5 & 7 & 24 \\
\hline Kafa travması & 10 & 18.2 & 22.00 & $\begin{array}{c}10.1 \\
7\end{array}$ & 20.0 & 10 & 40 \\
\hline $\begin{array}{l}\text { Ekstremite } \\
\text { fraktürü }\end{array}$ & 6 & 10.9 & 23.50 & $\begin{array}{c}12.5 \\
0\end{array}$ & 19.0 & 12 & 45 \\
\hline \begin{tabular}{l} 
Toplam \\
\hline
\end{tabular} & $\mathbf{3 6}$ & $\mathbf{6 7 . 3}$ & $\mathbf{1 6 . 2 6}$ & $\mathbf{9 . 5 5}$ & $\mathbf{1 2 . 0}$ & $\mathbf{7}$ & $\mathbf{4 5}$ \\
\hline
\end{tabular}

intratorasik organ yaralanması arasinda bilinen bir ilişki yoktur (4,14). Hastalar miyokardial kontüzyon ve akciğer parankim yaralanmaları yönünden hastalar dikkatli değerlendirilmelidir. Hastalara başvuru anında EKG ve CK, CK-MB değerleri incelenmelidir. Şüpheli durumlarda en uygun ve hizlı tanı yöntemi ekokardiografi ile incelemedir $(1,10,15)$. Brookes ve $\operatorname{ark}(1)$. SF ile birlikte miyokard kontüzyonunu $\% 1.3$ ile \%21.4 arasinda bildirmektedir. Ancak biz serimizde miyokardial hasarı olan hastaya rastlamadik.

SF'de hastanede yatış süresi sternum patolojisinden çok eşlik eden diğer travmatik patolojilere bağlıdır (16). Izole SF genellikle benign seyreden ve kendi kendine iyileşen bir durum olarak göze çarpmaktadır $(9,16)$. İzole SF saptanan hastalarda analjezik tedavi ve solunum egzersizleri genellikle yeterli görülmektedir $(9,10,16)$. Eşlik eden intratorasik patolojiler olmasi durumunda hastanin prognozunu bu patolojiler belirler. Serimizde izole SF saptanan hastalar için hastanede yatış süreleri ile komplike hastaların yatış süreleri karşılaştırıldığında istatistiksel olarak anlamlı şekilde komplike hastaların daha uzun süre yatarak tedavi görmüş olması bunun bir sonucudur. Ayrica hastalarda mortaliteye sebep olan komplikasyonların da SF'nin kendisine ait komplikasyonlar değil eşlik eden travmaya bağlı patolojiler nedeniyle ortaya çıkan komplikasyonlar olduğu görülmüştür. 


\section{Sonuç}

Sonuç olarak SF toraks travması geçiren hastalarda seyrek olarak rastlanan bir komplikasyondur. İzole SF genellikle analjezik tedavi ve solunum egzersizi

\section{KAYNAKLAR}

1. Brookes JG, Dunn RJ, Rogers IR. Sternal fractures: a retrospective analysis of 272 cases. J Trauma 1993;35:46-54

2. Roy-Shapira A, Levi I, Khoda J. Sternal fractures: a red flag or a red herring? J Trauma 1994;37:59-61

3. Porter RS, Zhao N. Patterns of injury in belted and unbelted individuals presenting to a trauma center after motor vehicle crash: seat belt syndrome revisited. Ann Emerg Med 1998;32:418424

4. Hills MW, Delprado AM, Deane SA. Sternal fractures: associated injuries and management. J Trauma 1993;35:55-60

5. Bilgin M, Akçalı Y, Hasdıraz L, et al. Isolated sternal fractures: a hallmark of violent injury. Türk Gögüs Kalp Damar Cer Derg 2009;17:33-35

6. Richardson JD, Grover FL, Trinkle JK. Early operative management of isolated ile tedavi edilebilir. Bununla birlikte SF maruz kalınan travmanın şiddetini gösteren önemli bir göstergedir. Eşlik eden komplikasyonları, intratorasik organlar ve diğer sistemler üzerindeki patolojiler yönünden dikkatli incelenmesi gereken bir durumdur. sternal fractures. J Trauma 1975; 15:156158

7. Crestanello JA, Samuels LE, Kaufman MS, et al. Sternal fracture with mediastinal hematoma: delayed cardiopulmonary sequelae. J Trauma 1999;47:161-164

8. Saab M, Kurdy NM, Birkinshaw R. Widening of the mediastinum following a sternal fracture. Int $\mathrm{J}$ Clin Pract 1997;51:256-257

9. Velissaris T, Tang AT, Patel A, et al. Traumatic sternal fracture: outcome following admission to a Thoracic Surgical Unit. Injury 2003;34:924-927

10. Celik B, Sahin E, Nadir A, et al. Sternum fractures and effects of associated injuries. Thorac Cardiovasc Surg. 2009;57:468-471.

11. Odell JA. Trauma to the chest wall and thoracic vertebrae. In Westaby ST, Odell
JA, editors, Cardiothoracic Trauma, London: Arnold, 1999. p:247-266

12. Rehring TF, Winter CB, Chambers JA, et al. Osteomyelitis and mediastinitis complicating blunt sternal fracture. J Trauma 1999;47:594-596

13. Kao CL, Chang JP, Chang CH. Acute mediastinal tamponade secondary to blunt sternal fracture. J Trauma 2000;48:157-158

14. Chiu WC, D'Amelio LF, Hammond JS. Sternal fractures in blunt chest trauma: a practical algorithm for management. Am J Emerg Med 1997;15:252-255

15. Gouldman JW, Miller RS. Sternal fracture: a benign entity? Am Surg 1997;63:17-19

16. Athanassiadi K, Gerazounis M, Moustardas M, et al. Sternal Fractures: Retrospective Analysis of 100 Cases. World J Surg 2002;26:1243-1246 